\title{
Modelling the Time on Unemployment Insurance Benefits
}

\author{
Govert E. Bijwaard* \\ Econometric Institute \\ Erasmus University Rotterdam \\ and IZA Bonn
}

Econometric Institute Report EI 2007-28

${ }^{*}$ Erasmus University Econometric Institute, P.O. Box 1738, 3000 DR Rotterdam, The Netherlands; Phone: (+31) 1040 81424; Fax: (+31) 1040 89162; E-mail: bijwaard@few.eur.nl This research is financially supported by the Netherlands Organisation for Scientific Research (NWO) nr. 451-04-011 


\title{
Modelling the Time on Unemployment Insurance Benefits
}

\begin{abstract}
A duration model based on the time on Unemployment Insurance (UI) benefits instead of a model based on the time till re-employment is more relevant from a cost-benefit perspective. The contribution of this paper is to extend the standard (mixed) Proportional Hazard model to account for an upper bound on the duration. We use a modified moverstayer model to this end and discuss the interpretation of the parameters. In an empirical application we compare the method with the standard analysis of unemployment duration. We also derive the expected UI-benefit costs implied by the model for some typical unemployed individuals.
\end{abstract}

Key words: UI-benefits; Maximum duration; Mixed proportional hazard; mover-stayer model

JEL classification: C41; J64; J65 


\section{Introduction}

Many empirical studies on unemployment duration use administrative data. Very often a limitation of these data is that the unemployed are only observed while receiving Unemployment Insurance (UI) benefits. The common solution to this problem is to take the observations that end with benefit exhaustion as censored observations. This implies that the duration of interest is the time to the next job. However, the duration of benefit receipt is of more interest for computing direct program costs. Then, the upper bound of the benefit duration should be taken into account.

The contribution of this paper is to extend the standard (mixed) Proportional Hazard model to account for an upper bound on the duration. We use a modified mover-stayer model to this end and discuss the interpretation of the parameters. In an empirical application we compare the method with the standard analysis of unemployment duration. We also derive the expected UI-benefit costs implied by the model for some typical unemployed individuals.

\section{Maximum duration in a duration model}

In duration analysis the hazard rate or intensity is usually modelled. A common way to accommodate the presence of observed characteristics is to specify a proportional intensity model, see a.o. Lancaster (1990)

$$
\lambda(t \mid x)=\lambda_{0}(t) e^{\beta^{\prime} x_{i}}
$$

where $\lambda_{0}(t)$ represents the baseline hazard, that is, the duration dependence of the intensity common to all individuals. The covariates affect the intensity proportionally.

Suppose that the duration of each individual has an, individual specific, upper bound of $\bar{t}_{i}$, say the maximum number of weeks an individual is eligible for UI-benefits. If a non-zero, albeit unknown, percentage $p$ of the individuals reach their upper bound, the survival conditional on not have reached the maximum duration is (for $0 \leq t \leq \bar{t}_{i}$ )

$$
S\left(t \mid \bar{t}_{i}, x_{i}\right)=p+(1-p) \frac{\exp \left(-\int_{0}^{t} \lambda_{0}(s) e^{\beta^{\prime} x_{i}} d s\right)-\exp \left(-\int_{0}^{\bar{t}_{i}} \lambda_{0}(s) e^{\beta^{\prime} x_{i}} d s\right)}{1-\exp \left(-\int_{0}^{\bar{t}_{i}} \lambda_{0}(s) e^{\beta^{\prime} x_{i}} d s\right)}
$$


Thus a fraction of $1-p$ the individuals will make a transition before their maximum duration is reached. This is an extension of a so-called mover-stayer or 'split-population' model that accounts for an upper bound in the duration. The mover-stayer approach was first applied in the social sciences to model the recidivism of criminals by Schmidt and Witte (1989). It assumes that a latent group of individuals have a zero probability to make a transition, the stayers. Here the stayers are those individuals that reach their upper bound on the duration.

If we do not account for possible missing variables, the parameter estimator may be biased. It may lead to spurious negative duration dependence. Therefore, it is important to allow for individual-specific unobserved heterogeneity in the model. The conventional way to capture this effect is to include a multiplicative random variable in the hazard to get a mixed proportional hazard model with hazard

$$
\lambda\left(t \mid v_{i}, x_{i}\right)=v_{i} \lambda_{0}(t) \exp \left(\beta^{\prime} x_{i}(t)\right)
$$

where the $v_{i}>0$ are i.i.d. random variables with (mixture) distribution function $G(v)$. The Gamma distribution with mean one and variance $\sigma^{2}$ is most often chosen to represent the unobserved heterogeneity.

The latent probability of reaching the maximum duration lays between zero and one and can be modelled in a logit form and it can depend on observed characteristics of the individuals, $p\left(x_{i}\right)=e^{\gamma^{\prime} x_{i}} /\left(1+e^{\gamma^{\prime} x_{i}}\right)$. The density of observed UI-benefit duration is now a mixture of a discrete distribution, the probability of reaching the upper bound, and a continuous distribution, the probability to leave the UI-system before benefit exhaustion, i.e.

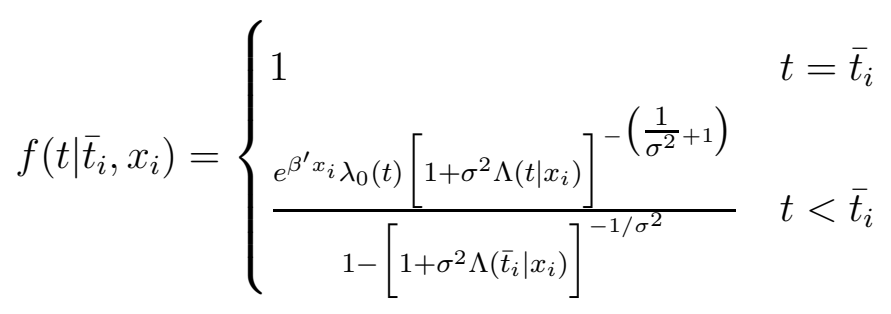

where $\Lambda\left(t \mid x_{i}\right)=\int_{0}^{t} \lambda_{0}(s) e^{\beta^{\prime} x_{i}} d s$. A very flexible assumption is to use a baseline hazard that is constant on $M$ intervals. Let the intervals $I_{m}(t)=I\left(d_{m-1} \leq t<d_{m}\right)$ for $m=1, \ldots, M$ with $d_{0}=0$ and $d_{M}=\max _{i}\left\{\bar{t}_{i}\right\}$ be the intervals on which we define the baseline hazard. Then, the baseline hazard is $\lambda_{0}(t)=\sum_{m=1}^{M} e^{\alpha_{m}} I_{m}(t)$. The parameters of the model can be obtained 
by standard maximum likelihood procedures. Note that the parameters of the probability of reaching the upper bound can be estimated solely based on a logit analysis of benefit exhaustion.

The interpretation of the parameters is not as clear as in the standard (M)PH model. Although conditional on being a mover, somebody who leaves the UI-system before benefit exhaustion, the hazard rate still exhibits the multiplicative structure, the unconditional hazard is non-linear in its components. However, in a cost-benefit analysis of the UI-system the expected costs per unemployment individual has a more relevance than the impact on the hazard rate out of UI-benefits. Given the estimated parameters the expected UI-duration is

$$
\begin{aligned}
& \mathrm{E}\left[T \mid \bar{t}_{i}, x_{i}\right]=p\left(x_{i}\right) \bar{t}_{i}+\frac{1-p\left(x_{i}\right)}{1-\left[1+\sigma^{2} e^{\beta^{\prime} x_{i}} \sum_{m=1}^{M} e^{\alpha_{m}}\left(d_{m}-d_{m-1}\right)\right]^{-1 / \sigma^{2}}} \\
& \times\left\{\sum_{m=1}^{M} \frac{e^{-\alpha_{m}-\beta^{\prime} x}}{1-\sigma^{2}}\left(\left[1+\sigma^{2} e^{\beta^{\prime} x_{i}} \sum_{j=1}^{m-1} e^{\alpha_{j}}\left(d_{j}-d_{j-1}\right)\right]^{-\frac{1}{\sigma^{2}}+1}-\left[1+\sigma^{2} e^{\beta^{\prime} x_{i}} \sum_{j=1}^{m} e^{\alpha_{j}}\left(d_{j}-d_{j-1}\right)\right]^{-\frac{1}{\sigma^{2}+1}}\right)\right. \\
& -\bar{t}_{i}\left[1+\sigma^{2} e^{\beta^{\prime} x_{i}} \sum_{m=1}^{M} e^{\alpha_{m}}\left(d_{m}-d_{m-1}\right]^{-1 / \sigma^{2}}\right\}
\end{aligned}
$$

and it is straightforward to derive the marginal effect, $\partial \mathrm{E}\left[T \mid \bar{t}_{i}, x\right] / \partial x$, at a given covariate vector. For a cost-benefit analysis one can either calculate the money value of the expected time on UI-benefits or calculate the marginal effect in money value.

\section{Empirical Application}

Between mid-1984 and mid-1985, the Illinois Department of Employment Security conducted a controlled social experiment. ${ }^{1}$ In the experiment, newly unemployed claimants were randomly divided into three groups: a Claimant Bonus Group, a Employer Bonus Group and, a control group. For the purpose of the present analysis we focus on the members of the control group. The sample contains 3641 individuals who start a new unemployment spell during the period. We have information on a limited set of explanatory variables: age, pre-unemployment earnings, race, gender and weekly benefit level (and dependence allowance).

\footnotetext{
${ }^{1} \mathrm{~A}$ complete description of the experiment and a summary of its results can be found in Woodbury and Spiegelman (1987).
} 
The central data base is an administrative source that only observes the unemployed while they receive UI-benefits. If an individual exhausts UI-benefits, the labor market status of that individual is unknown. At that time the maximum duration of receiving UI-benefits in Illinois was 26 weeks. Thus, the duration on UI-benefits has an upper bound of 26 weeks. Table 1 presents the estimation results and Figure 1 the unconditional 'baseline' hazard, the hazard for the reference individual. Note that in the model for UI-benefit duration the baseline hazard conditional on being a mover( only in this case equal to $\lambda_{0}(t)$ ) implies a positive duration dependence while the unconditional hazard exhibits a negative duration dependence. 
Table 1: Parameter estimates of MPH hazard model with and without maximum duration.

\begin{tabular}{|c|c|c|c|}
\hline & \multirow{2}{*}{$\begin{array}{c}\text { Standard MPH } \\
\text { hazard }\end{array}$} & \multicolumn{2}{|c|}{ "Maximum duration } \\
\hline & & hazard & Prob. exhaust benefits \\
\hline \multirow{3}{*}{ age } & $\beta$ & $\beta$ & $\gamma$ \\
\hline & $-0.152^{* *}$ & -0.042 & $0.225^{* *}$ \\
\hline & $(0.031)$ & $(0.051)$ & $(0.048)$ \\
\hline \multirow[t]{2}{*}{ age-squared } & $0.066^{*}$ & 0.066 & $-0.100^{*}$ \\
\hline & $(0.029)$ & $(0.049)$ & $(0.044)$ \\
\hline \multirow[t]{2}{*}{ Log Base Period Earnings } & $0.318^{* *}$ & 0.124 & $-0.477^{* *}$ \\
\hline & $(0.063)$ & $(0.106)$ & $(0.097)$ \\
\hline \multirow[t]{2}{*}{ black } & $-0.538^{* *}$ & $-0.201^{*}$ & $0.735^{* *}$ \\
\hline & $(0.057)$ & $(0.098)$ & $(0.078)$ \\
\hline \multirow[t]{2}{*}{ male } & $0.116^{*}$ & -0.003 & $-0.191^{* *}$ \\
\hline & $(0.046)$ & $(0.078)$ & $(0.070)$ \\
\hline \multirow[t]{4}{*}{ Log Weekly benefits } & $-0.501^{* *}$ & -0.288 & $0.747^{* *}$ \\
\hline & $(0.106)$ & $(0.187)$ & $(0.163)$ \\
\hline & & & $-0.198^{* *}$ \\
\hline & & & $(0.064)$ \\
\hline \multicolumn{4}{|l|}{ baseline hazard } \\
\hline$\alpha_{1}(0$ to 2 weeks $)$ & $\begin{array}{c}-3.222^{* *} \\
(0.070)\end{array}$ & $\begin{array}{c}-3.002^{* *} \\
(0.098)\end{array}$ & \\
\hline \multirow[t]{2}{*}{$\alpha_{2}(2$ to 10 weeks $)$} & $-3.376^{* *}$ & $-2.256^{* *}$ & \\
\hline & $(0.051)$ & $(0.091)$ & \\
\hline \multirow[t]{2}{*}{$\alpha_{3}$ (10 to 20 weeks) } & $-3.684^{* *}$ & $-1.692^{* *}$ & \\
\hline & $(0.056)$ & $(0.167)$ & \\
\hline \multirow[t]{2}{*}{$\alpha_{4}(20$ to 22 weeks $)$} & $-3.470^{* *}$ & -0.402 & \\
\hline & $(0.100)$ & $(0.264)$ & \\
\hline \multirow[t]{2}{*}{$\alpha_{5}(22$ to 24 weeks $)$} & $-3.432^{* *}$ & 0.055 & \\
\hline & $(0.101)$ & $(0.315)$ & \\
\hline \multirow[t]{2}{*}{$\alpha_{6}(24 \text { to } 26 \text { weeks })^{\mathrm{a}}$} & $-3.336^{* *}$ & $1.700^{* *}$ & \\
\hline & $(0.100)$ & $(0.398)$ & \\
\hline \multirow[t]{2}{*}{$\ln \left(\sigma^{2}\right)$} & -15.426 & -0.269 & \\
\hline & $446.563)$ & $(0.230)$ & \\
\hline Log-likelihood & 4774.930 & -8654.748 & \\
\hline
\end{tabular}

${ }^{\mathrm{a}}$ In the standard MPH model the last interval is 24 weeks till $\infty$.

Notes: Standard errors are shown in parentheses. ${ }^{*} p<0.05 ;{ }^{* *} p<0.01$ 
From the implied expected duration in UI-benefits it is straightforward to calculate the expected UI-costs for any individual. Table 2 shows the expected cost of UI-benefits payments for some typical unemployed individuals.

Table 2: Expected UI costs

\begin{tabular}{l|cccc}
\hline \hline & \multicolumn{4}{|c}{ UI weekly benefit } \\
& $\$ 126.50$ & $\$ 51$ & $\$ 161$ & $\$ 209$ \\
\hline base & $\$ 2230$ & $\$ 735$ & $\$ 2974$ & $\$ 4045$ \\
black & $\$ 2621$ & $\$ 903$ & $\$ 3447$ & $\$ 4616$ \\
male & $\$ 2141$ & $\$ 704$ & $\$ 2861$ & $\$ 3901$ \\
age $=20$ & $\$ 1956$ & $\$ 634$ & $\$ 2627$ & $\$ 3605$ \\
age $=40$ & $\$ 2281$ & $\$ 754$ & $\$ 3038$ & $\$ 4125$ \\
base Period Earnings $=\$ 1533$ & $\$ 2360$ & $\$ 787$ & $\$ 3135$ & $\$ 4244$ \\
base Period Earnings $=\$ 4267$ & $\$ 2089$ & $\$ 683$ & $\$ 2796$ & $\$ 3820$ \\
\hline \hline
\end{tabular}

A base individual is a white female aged 33 with $\$ 126.50$ weekly benefit and base period earnings of $\$ 2511$.

\section{Further Research}

Another application of the described model is the (cost-benefit) analysis of disability benefits. In most Western countries disability benefits cease after retirement. In fact, everybody leaves the potential workforce when reaching the retirement age. An issue hardly ever mentioned in the analysis of labour market transitions is that for some individuals labour market transitions occur at a very low rate. Therefore, these individuals may stay on disability benefits till they reach the retirement age of 65 . This implies that the duration on disability has a upper bound of the time till retirement. Bijwaard and Veenman (2007) apply this argument to model the duration on disability benefits for different ethnic groups in The Netherlands.

\section{References}

Bijwaard, G. E. and J. Veenman (2007). Unequal chances on the transitional labour market, the case of the netherlands. Discussion Paper No. 29??, IZA.

Lancaster, T. (1990). The Econometric Analysis of Transition Data. Cambridge University Press. 
Schmidt, P. and A. D. Witte (1989). Predicting criminal recidivism using 'split population' survival time models. Journal of Econometrics 40, 141-159.

Woodbury, S. A. and R. G. Spiegelman (1987). Bonuses to workers and employers to reduce unemployment: Randomized trials in Illinois. American Economic Review 77, 513-530.

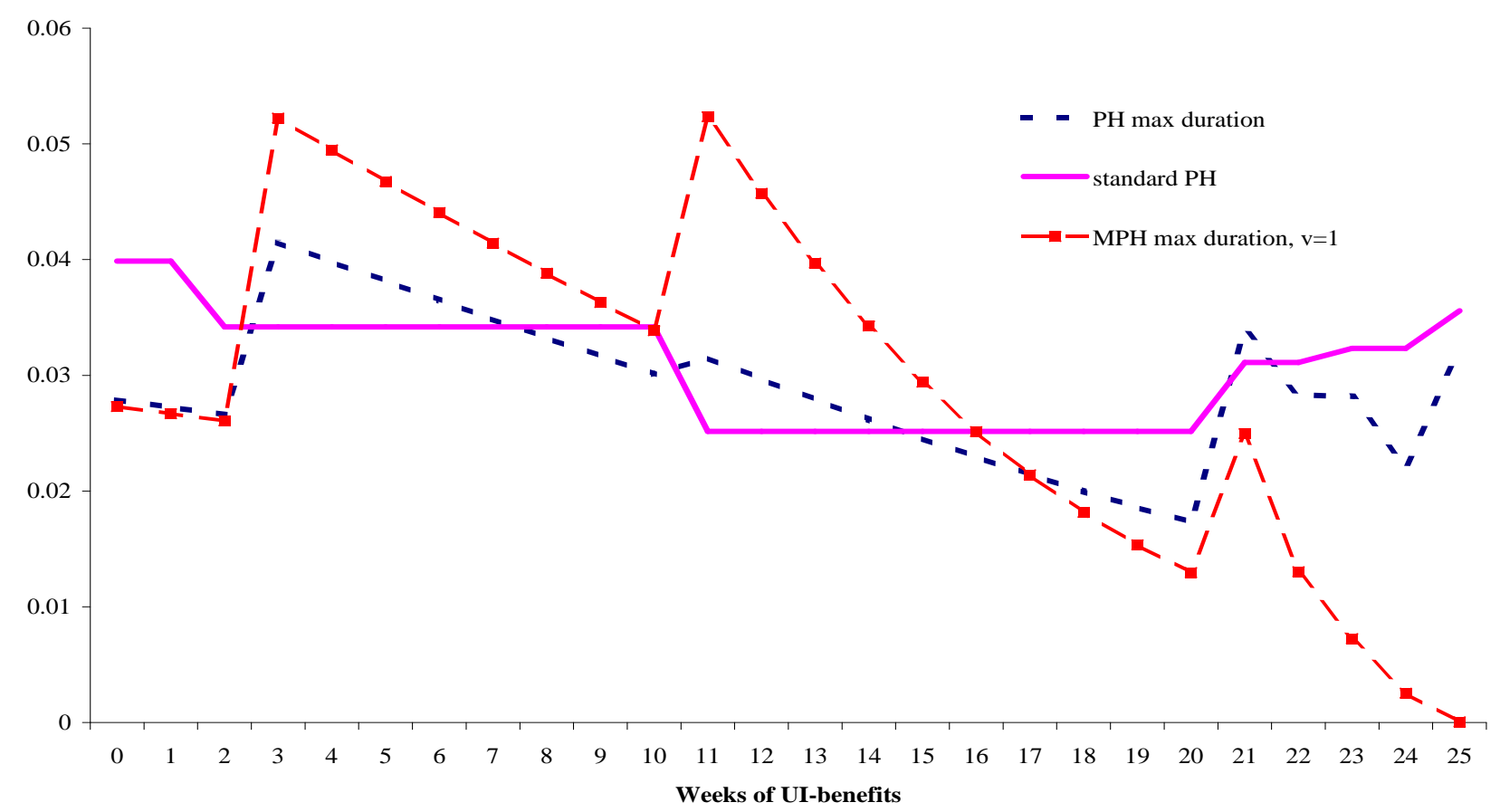

Figure 1: Estimated baseline hazard. 